\title{
Predictive Value of Neutrophil Lymphocyte Ratio and Wells Score in Patients with Pulmonary Embolism after Trauma \\ M İçer ${ }^{1}$, Y Zengin ${ }^{1}$, HM Durgun ${ }^{1}$, E Gündüz ${ }^{1}$, R Dursun $^{1}$, M Gem ${ }^{2}$, M Taylan $^{3}$, C Güloğlu ${ }^{4}$
}

\begin{abstract}
Objective: Trauma patients have a high risk of deep vein thrombosis and pulmonary embolism. There are very few studies that apply Wells scoring, which is the most commonly used instrument for the early diagnosis of the trauma patients who are at risk of and suspected of suffering from pulmonary embolism. In recent years, the neutrophil lymphocytes ratio in peripheral blood has been suggested to be used in pulmonary embolism diagnosis as a good marker of inflammation. This study aims to investigate the efficiency of NLR and the Wells score for predicting pulmonary embolism in patients who are admitted to the emergency department due to trauma.
\end{abstract}

Methods: In this study, 7,321 trauma patients were retrospectively examined. Following the trauma, 76 patients who were admitted to the computed tomographic pulmonary angiography (CTPA) was taken in order to evaluate the potential existence of pulmonary embolism within one month after the first trauma during their acute hospitalization or they represented to the emergency department for symptoms. Patients were divided into two groups (i.e., a pulmonary embolism group and a non-pulmonary emboli group), according to the tomography results and after the NLR and Wells scoring were calculated and compared according to the patients' clinical findings at the time of application.

Results: In this study, 36 people were in the pulmonary embolism group and 40 people were in the nonpulmonary embolism group. In the analysis of the receiver operator characteristics when the cut-off value was 3.2 for NLR, pulmonary embolism was detected with $94.4 \%$ sensitivity and $87.5 \%$ specificity. When the cut-off is 4 for the Wells score, pulmonary embolism was detected with $83.3 \%$ sensitivity and $100 \%$ specificity.

Conclusion: NLR and Wells scoring may be used to predict acute pulmonary embolism in trauma patients.

Keywords: Neutrophil lymphocyte ratio, pulmonary embolism, trauma, well score

From: ${ }^{1}$ Dicle University, Faculty of Medicine, Emergency Medicine Department, Diyarbakır, Turkey, ${ }^{2}$ Dicle University, Faculty of Medicine, Orthopedics and Traumatology Department, Diyarbakır, Turkey, ${ }^{3}$ Dicle University, Faculty of Medicine, Department of Chest Diseases, Diyarbakır, Turkey and ${ }^{4}$ Dicle University, Faculty of Medicine, Emergency Medicine Department, Diyarbakır, Turkey.

Correspondence: Dr M Ǐcer, Department of Emergency Medicine, Faculty of Medicine, Dicle University, 21280, Diyarbakir, Turkey. Fax: +90 412248 8440, email: drmicer@ gmail.com 


\section{INTRODUCTION}

Pulmonary embolism (PE) is a disease that is known to have a high mortality and morbidity rate (1). Trauma patients run a high risk of deep vein thrombosis and PE. The PE risk factors among trauma patients include older age, lower extremity and pelvic fractures, head and spinal cord trauma, venous trauma, prolonged immobilization and recent major surgeries $(2$, $3,4,5)$. For the early diagnosis and treatment of the patients who are at risk and suspected of experiencing PE, several diagnostic scoring systems were developed (6). The commonly used tests include the Wells score, Geneva score, Miniati score and the Charlotte rule. The most frequently used and accepted of these tests is the Wells score $(7,8)$. There are a few studies in which Wells scoring is applied in trauma patients (9). Therefore, the reliability of this scoring regarding PE prediction in trauma patients is not completely known and new studies are needed.

Previous studies indicate that PE is associated with early white blood cell (WBC) increase after thromboembolic events. Such a situation is associated with recurrent venous thromboembolism, major bleeding and mortality $(10,11)$. Besides, increased WBC number was indicated to be a tool rather than a prognostic value (12). In recent years, when the neutrophil-lymphocyte ratio (NLR) in peripheral blood is compared with WBC, it was suggested to be a better inflammation marker (13). NLR was stated to be a developing marker of inflammation and an independent predictor of the mortality associated with cardiac disease and cancer, as well as being a beneficial marker in cardiovascular diseases (14). However, there is no study about whether NLR is a predictor in pinpointing PE in trauma patients. The aim of this study is to investigate the efficiency of NLR and Wells scoring use in predicting PE in the patients admitted to the emergency department due to trauma. 


\section{MATERIALS AND METHODS}

\section{Study Design}

In this retrospective study, the files of 7,321 trauma patients who were admitted to the emergency department of the university hospital (a tertiary care hospital) from January 1, 2009, to December 31, 2014, were examined. Eighty-one of these patients were admitted to the computed tomographic pulmonary angiography (CTPA) was taken in order to evaluate the potential existence of $\mathrm{PE}$ within one month after the first trauma during their acute hospitalization or they represented to the emergency department for symptoms. Patients whose data could not be entirely obtained from the from hospital information system, patients who were under 18 years of age, patients who had been diagnosed with PE via methods other than CT, 5 patients who were found to have active cancer, as well as those with acute coronary syndrome, congestive heart failure, a chronic obstructive pulmonary disease exacerbation period, chronic inflammation or any other disease or systemic infection, were excluded from the study. The participant pool consisted of 76 patients who were placed in two groups, according to CTPA results - those with PE and those without PE. The format of the effort was a retrospective cross-sectional study.

\section{Laboratory and Radiologic Analyses}

In the study, the WBC, neutrophil and lymphocyte count, NLR, D-dimer, troponin-I and arterial blood gas $(\mathrm{pO} 2, \mathrm{pCO} 2, \mathrm{pH})$ values were obtained from the emergency department applications where the CTPA taken after trauma. Values were considered to be positive when the D-dimer was $>500 \mathrm{mg} / \mathrm{L}$ and troponin-I was $>$ 0:06 ng/ml. Pulmonary embolism was diagnosed with the detection of the images of CTPA that were compatible with PE and taken by a 64-detector computed tomography device (Brilliance CT scanner, Philips Medical 
Systems, Cleveland, Ohio, USA) by using the PE protocol (with $120 \mathrm{~mL}$ of intravenous contrast material, a 35-cm field of view and a thickness of $3 \mathrm{~mm}$ ) (15).

\section{Wells Score}

The patients' Wells scores were calculated as Wells scorings' three-level score (alternative) and two-level score (traditional), according to clinical findings at the time of admission (16).

\section{Statistical Analyses}

Statistical analysis was performed by using SPSS version 18.0 (SPSS Inc., Chicago, IL, USA). Data were tested for normality by using the Kolmogorov-Smirnov normality test. Continuous variables were shown as a mean \pm standard deviation or median interquartile ranges (IQR) as applicable. Categorical data were analyzed by using the chi-square test (the student's t-test was used for normally distributed data). The mean difference among the groups was compared by the student's t-test; otherwise, the comparison of the mean values was performed by the Mann-Whitney U test. Nominal data was analyzed by using Pearson's chi-square test. For the diagnosis of PE, the total of maximum specificity and sensitivity was given for the significant test and evaluated by the NLR optimal cut-off point receiver operating characteristic (ROC) analysis. Whether or not a predictive on the PE diagnosis of NLR is statistically significant was evaluated by multiple logistic regression analysis after all potential confounding factors were adjusted. For each independent variable, the odds ratios (ORs) and 95\% confidence intervals (CIs) were calculated. A P-value of $<0.05$ was considered statistically significant. 


\section{Results}

In this study of the 76 patients to whom CTPA was taken with the suspect of PE after trauma in emergency department, 40 were female $(52.6 \%)$ and 36 were male $(47.4 \%)$. The PEdetected group included 36 patients $(47.4 \%)$ and the non-PE detected group consisted of 40 patients $(52.6 \%)$ as a conclusion of the CTPA that was taken. The clinical and sociodemographic characteristics of the patients are presented in Tables 1 and 2. The mean post-

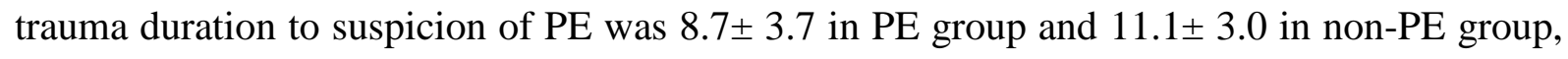
also there were statically significant difference among them $(\mathrm{p}=0.004)$ (Table 2).

When the groups are compared in terms of trauma mechanism, predisposing factors and existing fracture type, there are statistically significant differences in the PE group in comparison to the non-PE group (i.e., in terms of having experienced a traffic accident, a simple fall, fracture or lower extremity fracture) (the $\mathrm{p}$ values are, respectively, $0.011 ; 0.000$; $0.000 ; 0.000)$. In terms of admission symptoms and hemodynamic parameters, when the PE group and the non-PE group were compared, there was a statistically significant difference among them in terms of shortness of breath, chest pain, hemoptysis, weakness, leg pain and tachypnea (the $\mathrm{p}$ values are, respectively, $0.003 ; 0.005 ; 0.003 ; 0.000 ; 0.000 ; 0.000$ ). The Glasgow coma scale was significantly lower in the PE group in comparison to the non-PE group $(\mathrm{p}<0.001)$

When the groups were compared in terms of lymphocyte count and NLR, while the lymphocyte count in the PE group was statistically lower than in the non-PE group (p $<0.001$ ), the Wells score was statistically higher in the PE group than in the non-PE group (p $<0.001)$. Also, number of patients that had likely PE score were excess in the Wells PE group than in the non-PE group $(\mathrm{p}<0.001)$. With the receiver operator for NLR in the characteristics 
analysis cut-off value was 3.2 with sensitivity and $94.4 \%$ and $87.5 \%$ specificity and the Wells score inside the cut-off for 4 and a sensitivity of $83.3 \%$ and $100 \%$ specificity were determined to predict the PE development (Figure 1). Three patients (3.9\%) died during the follow-up period.

\section{DISCUSSION}

PE after trauma is a known complication in recent studies. It is seen in varying proportions from less than $1 \%$ to $24 \%$ and it is followed by mortality in varying ratios up to $26 \%(17,18$, 19). However, there were no significant differences in our study, in terms of the clinical and socio-demographic characteristics of the patients, from previous research, that the most common trauma mechanism is traffic accidents and the symptoms are shortness of breath complaints, chest pain, hemoptysis, weakness and leg pain, as well as patients' tachypnea. Fractures were among predisposing factors, and fractures of the lower extremities in particular were found to be a significant risk factor in detecting patients with PE after trauma.

In this study, we have investigated the predictive value of NLR at the time of hospital admission due to trauma for predicting PE in those patients. According to the current literature review, our study is the first in which NLR was used to predict PE in trauma patients. NLR was significantly higher in the PE group in comparison to the non-PE group. The baseline NLR value may predict PE in trauma patients independent of socio-demographic and clinical data. Besides, the cut-off value for NLR was detected to be 3.2 with a good specificity and an acceptable sensitivity. Our study results indicate that the use of NLR in predicting the development of PE in trauma patients may be a strong and cheap parameter. 
In recent studies, leukocyte counts and their sub-type ratios are accepted as an inflammation indicator in cardiovascular patients $(20,21)$. However, in acute PE, data is limited regarding the role of inflammation. In a prospective study that investigated prognostic factors in acute PE, high and low leukocyte counts (WBC $<4.0 \times 10^{9} / \mathrm{L}$ or $>10.0 \times 10^{9} / \mathrm{L}$ ) were important for 14-day mortality (22). In the study about the prognostic value of NLR for mortality in acute PE, it is stated that NLR can be used both for mortality as a prognostic factor and for the purpose of diagnosis (23). In trauma patients, the increased NLR levels in our results indicate the close and independent relationship between NLR and supports the inflammation role in acute PE after trauma.

In a study related to the lymphocyte population in blood after multiple traumas, it is stated that lymphocyte functions are affected by a decrease in the total lymphocytes as the indicator of cell-mediated immunity (24). In addition, it is suggested that cytokines release from stimulated neutrophils may be responsible for observed vascular injury (25). In our study, the NLR increase was detected to be a result of the increased neutrophil count and the decreased lymphocyte count. NLR that can be calculated easily can be used as a PEindependent risk factor in trauma patients.

To date, although many scoring systems, such as the Glasgow Coma Score (GCS), Injury Severity Score and Abbreviated Injury Score, were used to evaluate trauma patients, there is no ideal scoring system that indicates the trauma severity and prognosis of trauma patients $(26,27)$. In our study, the GCS in the PE group is significantly lower than in the nonPE group, which indicates that trauma severity and PE risk increase in trauma patients.

Current guidelines suggest a prognostic evaluation to classify the patients according to risk groups after an acute PE diagnosis. The PE severity index, Geneva and Wells scoring 
systems are among the most recommended systems (16). The commonly accepted Wells score has a predictive value in detecting PE risk in hospitalized patients $(28,29,30,31)$. However, recently, its efficient value in trauma and other patient populations has been investigated ( 7 , $32,33,34)$. In a study that is one of the few studies conducted in trauma patients, the Wells score has been detected to be less applicable, especially in orthopedic traumas (9). However, none of these scoring systems consider the parameters such as NLR, WBC or lymphocyte count. In our study, which included a two-level score evaluation of Wells scoring, the number of trauma patients classified as likely PE was significantly higher in the PE group than the non-PE group. Accordingly, we consider that Wells scoring can be used in PE prediction in trauma patients.

There were some limitations in our study. First of all, this research had a relatively smaller sample dimension and, for this reason, it is an observational, single-center and retrospective study composed of a variety of variables that cannot be calculated. Besides, we cannot compare some other inflammatory markers, such as C-reactive protein and fibrinogen with NLR, since they do not routinely work in a study population. The patients suspected of PE who died before diagnosis and whose data was insufficient were excluded from the study.

\section{CONCLUSION}

In conclusion, increased NLR is associated with increased PE in trauma patients as a simple non-specific marker of inflammation. Due to the fact that it is a common and inexpensive blood count test, it can be used as a new device for PE risk classification. Additionally, Wells scoring can be another method to be used in PE prediction in trauma patients. Also, we consider that new scoring systems including NLR and particular subtypes of leukocytes will be developed to be used in PE predictions among trauma patients and they will be capable of 
Ǐcer et al

enlightening the reduction of PE. For this reason, the role of NLR and Wells scoring in prediction of acute PE in trauma patients must be investigated in prospective randomized studies.

\section{Conflict of Interest}

Authors declared that there are no conflicts of interest. 


\section{REFERENCES}

1. Varol A, Kokturk N, Kilic H, Aydogdu M, Ekim NN. The role of quantitative D-dimer levels in the follow-up and differential diagnosis of pulmonary thromboembolism and community acquired pneumonia. Turk J Med Sci 2012; 42: 639-47.

2. Geerts WH, Bergqvist D, Pineo GF, Heit JA, Samama CM, Lassen MR, Colwell CW; American College of Chest Physicians. Prevention of venous thromboembolism: American College of Chest Physicians Evidence-Based Clinical Practice Guidelines (8th Edition). Chest 2008;133(6):381S-453S.

3. Geerts WH, Code KI, Jay RM, Chen E, Szalai JP. A prospective study of venous thromboembolism after major trauma. N Engl J Med. 1994;331(24):1601-1606.

4. Knudson MM, Ikossi DG, Khaw L, Morabito D, Speetzen LS. Thromboembolism after trauma: an analysis of 1602 episodes from the American College of Surgeons National Trauma Data Bank. Ann Surg 2004;240:490-496.

5. Benns M, Reilly P, Kim P. Early pulmonary embolism after injury: a different clinical entity? Injury. 2014;45(1):241-244.

6. Lee CH, Hankey GJ, Ho WK, Eikelboom JW. Venous thromboembolism: diagnosis and management of pulmonary embolism. Med J Aust. 2005; 182(11):569-574.

7. Kruip MJ, Slob MJ, Schijen JH, van der Heul C, Buller HR. Use of a clinical decision rule in combination with D-dimer concentration in diagnostic workup of patients with suspected pulmonary embolism: a prospective management study. Arch Intern Med. 2002; 162(14):1631-1635.

8. Wells PS, Anderson DR, Rodger M, Ginsberg JS, Kearon C, Gent M, et al. Derivation of a simple clinical model to categorize patients probability of pulmonary embolism: increasing the models utility with the SimpliRED D-dimer. Thromb Haemost 2000; 83(3):416-420.

9. Young MD, Daniels AH, Evangelista PT, Reinert SE, Ritterman S, Christino MA, et al. Predicting pulmonary embolus in orthopedic trauma patients using the Wells score. Orthopedics. 2013;36(5):e642- e647.

10. Downing LJ, Strieter RM, Kadell AM, Wilke CA, Brown SL, Wrobleski SK, et al. Neutrophils are the initial cell type identified in deep venous thrombosis induced vein wall inflammation. ASAIO J. 1996;42(5):M677-M682. 
11. Afzal A, Noor HA, Gill SA, Brawner C, Stein PD. Leukocytosis in acute pulmonary embolism. Chest 1999;115(5):1329-32.

12. Masotti L, Cappelli R. C-reactive protein in elderly patients with suspected and confirmed pulmonary embolism. Clin Appl Thromb Hemost 2007;13(2):221-223.

13. Zahorec R. Ratio of neutrophil to lymphocyte counts - rapid and simple parameter of systemic inflammation and stress in critically ill. Bratisl Lek Listy 2001;102(1):5-14.

14. Shen XH, Chen Q, Shi Y, Li HW. Association of neutrophil/lymphocyte ratio with long-term mortality after ST elevation myocardial infarction treated with primary percutaneous coronary intervention. Chin Med J (Engl) 2010; 123: 3438-43.

15. Schoepf UJ, Costello P. CT angiography for diagnosis of pulmonary embolism: state of the art. Radiology. 2004;230(2):329-337.

16. Konstantinides S, Torbicki A, Agnelli G, Danchin N, Fitzmaurice D, Galiè N, et al. 2014 ESC Guidelines on the Diagnosis and Management of Acute Pulmonary Embolism. Rev Esp Cardiol (Engl Ed). 2015 Jan;68(1):64.

17. Schultz DJ, Brasel KJ, Washington L, Goodman LR, Quickel RR, Lipchik RJ, et al. Incidence of asymptomatic pulmonary embolism in moderately to severely injured trauma patients. J Trauma. 2004;56(4):727-31.

18. Knudson MM, Gomez D, Haas B, Cohen MJ, Nathens AB. Three thousand seven hundred thirty-eight posttraumatic pulmonary emboli: a new look at an old disease. Ann Surg. 2011;254(4):625-32.

19. Velmahos GC, Kern J, Chan LS, Oder D, Murray JA, Shekelle P. Prevention of venous thromboembolism after injury: an evidence-based report-part II: analysis of risk factors and evaluation of the role of vena caval filters. J Trauma. 2000;49: 140144.

20. Horne BD, Anderson JL, John JM, Weaver A, Bair TL, Jensen KR, et al. Which white blood cell subtypes predict increased cardiovascular risk? J Am Coll Cardiol 2005; 45(10): 1638-1643.

21. Acanfora D, Gheorghiade M, Trojano L, Furgi G, Pasini E, Picone C, et al. Relative lymphocyte count: a prognostic indicator of mortality in elderly patients with congestive heart failure. Am Heart J 2001;142 (1):167-173.

22. Zhu L, Wang C, Yang YH, Wu YF, Zhai ZG. Prognostic value of right ventricular dysfunction and derivation of a prognosticmodel for patients with acute pulmonary thromboembolism. Zhonghua Liu Xing Bing Xue Za Zhi 2009;30(2):184-188. 
23. Kayrak M, Erdoğan HI, Solak Y, Akilli H, Gül EE, Yildirim O, et al. Prognostic value of neutrophil to lymphocyte ratio in patients with acute pulmonary embolism: a restrospective study. Heart Lung Circ. 2014;23(1):56-62.

24. Menges T, Engel J, Welters I, Wagner RM, Little S, Ruwoldt R, et al. Changes in blood lymphocyte populations after multiple trauma: association with posttraumatic complications. Crit Care Med. 1999;27(4):733-740.

25. Li DB, Hua Q, Liu Z, Li J, Xu LQ, Wang S, et al. Association between inflammatory mediators and angiographic morphologic features indicating thrombus formation in patients with acute myocardial infarction. Chin Med J (Engl). 2009;122(15):17381742.

26. Chawda MN, Hildebrand F, Pape HC, Giannoudis PV. Predicting outcome after multiple trauma: which scoring system? Injury. 2004 ;35(4):347-358.

27. Brakenridge SC, Toomay SM, Sheng JL, Gentilello LM, Shafi S. Predictors of early versus late timing of pulmonary embolus after traumatic injury. Am J Surg. 2011;201(2):209-215.

28. Wells PS, Ginsberg JS, Anderson DR, Kearon C, Gent M, Turpie AG, et al. Use of a clinical model for safe management of patients with suspected pulmonary embolism. Ann Intern Med. 1998; 129(12):997- 1005.

29. Le Gal G, Righini M, Roy PM, Sanchez O, Aujesky D, Bounameaux H, et al. Prediction of pulmonary embolism in the emergency department: the revised Geneva score. Ann Intern Med. 2006; 144(3):165-171.

30. Wells PS, Anderson DR, Rodger M, Ginsberg JS, Kearon C, Gent M, et al. Derivation of a simple clinical model to categorize patients probability of pulmonary embolism: increasing the models utility with the SimpliRED D-dimer. Thromb Haemost. 2000; 83(3):416-420.

31. Geersing GJ, Erkens PM, Lucassen WA, Büller HR, Cate HT, Hoes AW, et al. Safe exclusion of pulmonary embolism using the Wells rule and qualitative D-dimer testing in primary care: prospective cohort study. BMJ. 2012; 345:e6564.

32. Wolf SJ, McCubbin TR, Feldhaus KM, Faragher JP, Adcock DM. Prospective validation of Wells Criteria in the evaluation of patients with suspected pulmonary embolism. Ann Emerg Med. 2004; 44(5):503-510. 
33. Rodger MA, Maser E, Stiell I, Howley HE, Wells PS. The interobserver reliability of pretest probability assessment in patients with suspected pulmonary embolism. Thromb Res. 2005; 116(2):101-107.

34. Runyon MS, Webb WB, Jones AE, Kline JA. Comparison of the unstructured clinician estimate of pretest probability for pulmonary embolism to the Canadian score and the Charlotte rule: a prospective observational study. Acad Emerg Med. 2005; 12(7):587-593. 
Table 1: Comparison of demographic, clinical, laboratory findings and Wells scores of patients according to the pulmonary embolism group.

\begin{tabular}{|c|c|c|c|}
\hline Variable & $\begin{array}{l}\text { Pulmonary Embolism } \\
\text { Group } \\
(\mathrm{n}=36)\end{array}$ & $\begin{array}{l}\text { Non Pulmonary } \\
\text { Embolism Group } \\
\qquad(\mathrm{n}=40)\end{array}$ & p- Value \\
\hline Age (years, mean \pm SD) & $56.7 \pm 18.8$ & $62.6 \pm 18.4$ & 0.18 \\
\hline \multicolumn{4}{|l|}{ Gender, n(\%) } \\
\hline Female & $19(47.5)$ & $21(52.5)$ & 0.98 \\
\hline Male & $17(47.2)$ & $19(52.8)$ & 0.98 \\
\hline \multicolumn{4}{|l|}{ Mechanism of injury, $n(\%)$} \\
\hline Simple fall & $14(65.0)$ & $26(35.0)$ & $<0.05$ \\
\hline Traffic accident & 16(69.6) & $7(30.7)$ & $<0.01$ \\
\hline Falls from height & $5(55.6)$ & $4(44.4)$ & 0.60 \\
\hline Gun shot wounds & $1(25.0)$ & $3(75.0)$ & 0.36 \\
\hline \multicolumn{4}{|l|}{ Fracture type, n (\%) } \\
\hline Upper extremity fractures & $2(50.0)$ & $2(50.0)$ & 0.91 \\
\hline Lower extremity fractures & $26(74.3)$ & $9(25.7)$ & $<0.001$ \\
\hline Pelvic fractures & $6(75.0)$ & $2(25.0)$ & 0.09 \\
\hline Vertebral fracture & $2(50.0)$ & $2(50.0)$ & 0.91 \\
\hline \multicolumn{4}{|c|}{ Presenting symptoms, n(\%) } \\
\hline Shortness of breath & $34(55.7)$ & $27(44.3)$ & $<0.01$ \\
\hline Chest pain & $25(62.5)$ & $15(37.5)$ & $<0.01$ \\
\hline Syncope & $1(50.0)$ & $1(50.0)$ & 0.94 \\
\hline Palpitation & $6(50.0)$ & $6(50.0)$ & 0.84 \\
\hline Hemoptysis & $7(100)$ & $0(0)$ & $<0.01$ \\
\hline Weakness & $10(100)$ & $0(0)$ & $<0.001$ \\
\hline Limbpain & $15(100)$ & $0(0)$ & $<0.001$ \\
\hline Accompanying diseases & & & \\
\hline
\end{tabular}




\begin{tabular}{llll}
\hline Hypertension & $10(47.3)$ & $11(52.7)$ & 0.98 \\
Diabetes Mellitus & $6(31.6)$ & $13(68.4)$ & 0.11 \\
CAD & $6(50.0)$ & $6(50.0)$ & 0.84 \\
COPD & $2(40.0)$ & $3(60.0)$ & 0.73 \\
CVD & $1(50.0)$ & $1(50.0)$ & 0.94 \\
CRF & $0(0)$ & $1(100)$ & 0.34 \\
Predisposing factors, $\mathbf{n}(\%)$ & & & 0.98 \\
Immobilization & $17(47.2)$ & $19(52.8)$ & 0.71 \\
Operation & $12(44.4)$ & $15(55.6)$ & 0.29 \\
Varices of leg & $1(50.0)$ & $1(50.0)$ & $<0.001$ \\
Fracture & $36(70.6)$ & $15(29.4)$ & 0.06 \\
Haemodynamic parameters,n(\%) & & & 0.06 \\
SystolicBP<100mmHg & $15(55.6)$ & $12(44.4)$ & $<0.001$ \\
Tachypnea(>20/ min) & $20(100)$ & $0(0)$ & 0.07 \\
Tachycardia(> 100/min) & $13(65.0)$ & $7(35.0)$ & 0.98 \\
Arterialoxygensaturation< & $190 \%$ & $21(52.5)$ & \\
Patient Outcome, $\mathbf{n}(\%)$ & $33(45.2)$ & & 0.06 \\
Discharge & $3(100)$ & $40(54.8)$ & \\
Dead & & & \\
\hline
\end{tabular}

SD: Standard deviation,CAD: Coronary artery disease; COPD: Chronic obstructive, pulmonary disease; BP: Blood pressure; WBC: White blood cell. 
Table 2: Laboratory findings, Wells scores and, Glasgow coma scores of patients according to the pulmonary embolism group.

WBC: White blood cell; NLR: Neutrophil lymphocyte ratio; GCS: Glasgow coma score; IQR: Inter quartile ranges

\begin{tabular}{|c|c|c|c|}
\hline & $\begin{array}{c}\text { Pulmonary } \\
\text { Embolism } \\
\text { Group } \\
(n=36)\end{array}$ & $\begin{array}{c}\text { Non Pulmonary } \\
\text { Embolism Group } \\
(\mathrm{n}=40)\end{array}$ & $\begin{array}{l}\text { p- } \\
\text { Value }\end{array}$ \\
\hline \multicolumn{4}{|l|}{ Laboratory findings } \\
\hline WBC $\left(10^{9} / \mathrm{L}\right)($ Mean \pm SD $)$ & $11.1 \pm 3.8$ & $12.3 \pm 4.8$ & 0.21 \\
\hline $\begin{array}{l}\text { Neutrophils }\left(10^{9} / \mathrm{L}\right) \\
(\text { Mean } \pm \text { SD })\end{array}$ & $8.4 \pm 3.6$ & $9.4 \pm 4.6$ & 0.28 \\
\hline $\begin{array}{l}\text { Lymphocytes }\left(10^{9} / \mathrm{L}\right) \\
(\text { Mean } \pm \mathrm{SD})\end{array}$ & $1.6 \pm 0.7$ & $3.9 \pm 2.1$ & $<0.001$ \\
\hline NLR(Mean \pm SD) & $5.1 \pm 1.7$ & $2.4 \pm 0.6$ & $<0.001$ \\
\hline Wells score(Median,IQR) & $6.0(4.5-7.5)$ & $1.5(1.5-1.5)$ & $<0.001$ \\
\hline Wells PE Likely, n(\%) & $28(100)$ & $0(0)$ & $<0.001$ \\
\hline Wells PE Unlikely, n(\%) & $8(16.7)$ & $40(83.3)$ & $<0.001$ \\
\hline GCS $($ Mean \pm SD $)$ & $10.3 \pm 1.2$ & $13.5 \pm 1.4$ & $<0.001$ \\
\hline $\begin{array}{l}\text { Post-trauma duration(day, } \\
\text { Mean } \pm \text { SD) }\end{array}$ & $8.7 \pm 3.8$ & $11.1 \pm 3.0$ & $<0.01$ \\
\hline
\end{tabular}




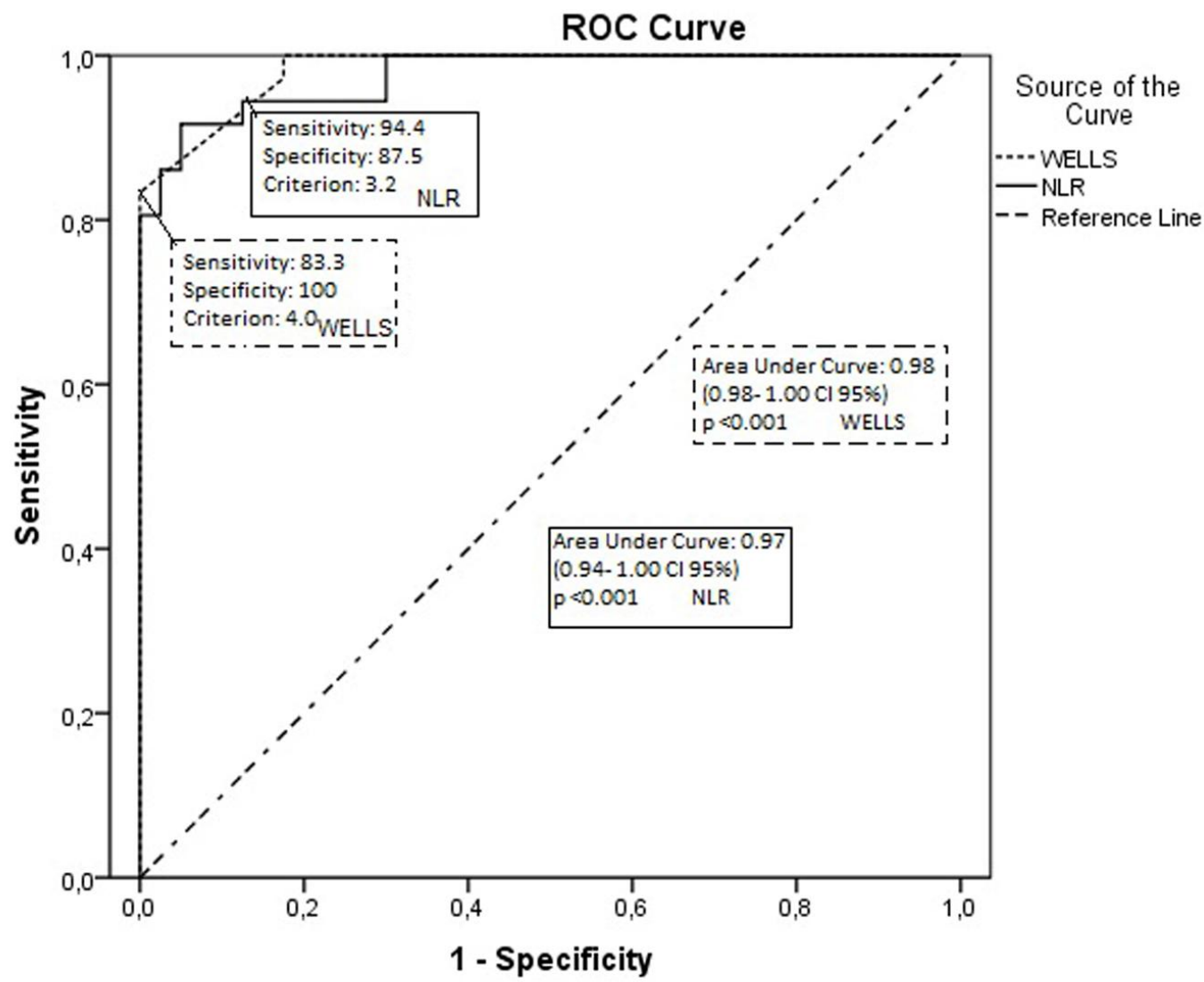

Figure 1: Receiver operator characteristics curves of NLR and Wells score to predict diagnose of pulmonary embolism. 